\title{
Suppression of Hepatic Apoptosis Induced by Acetaminophen Using a Combination of Resveratrol and Quercetin: An Association of Oxidative Stress and Interleukin-11
}

\author{
Suspensión de la Apoptosis Hepática Inducida por Acetaminofén Mediante una Combinación \\ de Resveratrol y Quercetina: Una Asociación de Estrés Oxidativo e Interleucina-1
}

\author{
Suliman Al Humayed ${ }^{1}$; Bahjat Al-Ani ${ }^{2}$ Abdullah S Shatoor ${ }^{1}$; Abbas O El Karib²; \\ Mohammad Dallak²; Samaa S Kamar ${ }^{3}$ \& Mohamed A Haidara ${ }^{2,4}$
}

\begin{abstract}
AL HUMAYED, S.; AL-ANI, B.; SHATOOR, A. S.; EL KARIB, A. O.; DALLAK, M.; KAMAR, S. S. \& HAIDARA, M. A. Suppression of hepatic apoptosis induced by acetaminophen using a combination of resveratrol and quercetin: An association of oxidative stress and interleukin-11. Int. J. Morphol., 38(1):83-90, 2020.
\end{abstract}

SUMMARY: We sought to determine whether the combined polyphenolic compounds, resveratrol and quercetin can substantially protect against modulation of hepatic biomarkers of apoptosis and survival, p53-Bax axis and B-cell lymphoma 2 (Bcl-2) in an animal model of acetaminophen-induced acute liver injury via the association of oxidative stress and interleukin-11 (IL-11). The model group of rats received a single dose of acetaminophen $(2 \mathrm{~g} / \mathrm{kg})$, whereas the protective group of rats was pre-treated for 7 days with combined doses of resveratrol $(30 \mathrm{mg} / \mathrm{kg})$ and quercetin $(50 \mathrm{mg} / \mathrm{kg})$ before being given a single dose of acetaminophen. All rats were then sacrificed 24 hours post acetaminophen ingestion. Acetaminophen overdose induced acute liver injury as demonstrated by profound liver parenchymal damage and increased levels of the liver injury enzymes, alanine aminotransferase (ALT) and aspartate aminotransferase (AST). Acetaminophen significantly ( $\mathrm{p}<0.05)$ modulated malondialdehyde (MDA), p53, apoptosis regulator Bax, Bcl-2, IL-11, interleukin-6 (IL-6), ALT, AST, superoxide dismutase (SOD), and glutathione peroxidase (GPx), which were significantly protected by resveratrol plus quercetin. We further demonstrated a significant $(\mathrm{p}<0.01)$ correlation between IL-11 scoring and the levels of $\mathrm{p} 53$, Bax, Bcl-2, and MDA. Thus, resveratrol plus quercetin effectively protect against acetaminophen-induced apoptosis, which is associated with the inhibition of oxidative stress and IL-11.

KEY WORDS: Acetaminophen; Acute liver injury; Apoptosis, Resveratrol; Quercetin; Rat model.

\section{INTRODUCTION}

Acute liver injury induced by acetaminophen (also known as paracetamol, or APAP) is common in both humans and experimental animal models after ingestion of an overdose of the drug (McGill et al., 2012). It is the most common agent of intentional self-harm and acetaminophen poisoning claimed the lives of 284 people aged 12 years and over between 1993-1996 in England and Wales, UK (Hawton et al., 2004). In addition, about $50 \%$ of acute liver failure admitted cases in the United States of America are caused by acetaminophen poisoning (Larson et al., 2005). Acetaminophen is metabolized in the liver and hepatotoxic metabolites that represents about $10 \%$ of the whole metabolites are rapidly inactivated by glutathione (GSH) to protect the hepatocytes (James et al., 2003). With drug overdose for example, the elevated levels of liver toxic metabolites, mainly $\mathrm{N}$-acetyl-p-benzoquinoimine (NAPQI) rapidly deplete GSH and covalently modify cellular proteins leading to the generation of high levels of reactive oxygen species (ROS) and the depletion of the ATP, which results in mitochondrial damage and hepatocyte injury (Hinson et al., 2004). However, it was postulated that depletion of $90 \%$ of GSH in hepatocytes is critically necessary for the development of cell necrosis (Henderson et al., 2000). In addition, hepatic inflammatory cytokines are also reported

\footnotetext{
${ }^{1}$ Department of Internal Medicine, College of Medicine, King Khalid University, Abha 61421, Saudi Arabia.

${ }^{2}$ Department of Physiology, College of Medicine, King Khalid University, Abha 61421, Saudi Arabia.

${ }^{3}$ Department of Medical Histology, Kasr Al-Aini Faculty of Medicine, Cairo University, Egypt.

${ }^{4}$ Department of Physiology, Kasr Al-Aini Faculty of Medicine, Cairo University, Egypt.

SOURCE OF FUNDING. This work was supported by the Research Deanship of King Khalid University, Abha, Saudi Arabia; Grant number KKUProject No. R.G.P1./66/40.
} 
AL HUMAYED, S.; AL-ANI, B.; SHATOOR, A. S.; EL KARIB, A. O.; DALLAK, M.; KAMAR, S. S. \& HAIDARA, M. A. Suppression of hepatic apoptosis induced by acetaminophen using a combination of resveratrol and quercetin: An association of oxidative stress and interleukin-11. Int. J. Morphol., 38(1):83-90, 2020.

to be involved in acetaminophen-induced liver injury (Blazka et al., 1996). However, dying hepatocytes (apoptosis pathway) upon hepatic injury induced by acetaminophen stimulate IL-11production, which supports compensatory proliferation of surrounding cells to maintain tissue hemostasis (Nishina et al., 2012). Furthermore, acetaminophen modulated the apoptotic protein p53 and the survival protein SIRT1 cell signaling to promote hepatocyte proliferation (Wang et al., 2015).

Quercetin and resveratrol are polyphenolic antioxidants found in fruits, vegetables, and grains (Cudmore et al., 2012). They have been widely known to have potent cardiovascular protective and therapeutic effects via scavenging ROS (Hung et al., 2000), anti-inflammatory effects (Rogerio et al., 2007; Al-Ani, 2013), inhibiting lipid peroxidation (Frankel et al., 1993), inhibiting platelet aggregation and thrombus formation (Bertelli et al., 1995), prevention of apoptosis and promotion of cell survival (Singh et al., 2011), and liver protection against hepatic sinusoidal obstruction and hepatic steatosis (Faghihzadeh et al., 2015; Zhang et al., 2017). Therefore, this study was designed to investigate the degree of protection by resveratrol and quercetin given in combination against acetaminopheninduced apoptosis and to monitor oxidative stress levels and IL-11 in the presence and absence of resveratrol plus quercetin.

\section{MATERIAL AND METHOD}

Reagents and assay kits. Quercetin (C15H10O7, CAS Number 117-39-5) was purchased from Sigma-Aldrich (St. Louis, MO, USA) and was prepared daily and freshly by dissolving in normal saline solution $(0.9 \% \mathrm{NaCl})$ to the final concentration of $50 \mathrm{mg} / \mathrm{ml}$. Resveratrol $(\mathrm{C} 14 \mathrm{H} 12 \mathrm{O} 3$, Cat No. R5010) was also purchased from Sigma-Aldrich (St. Louis, MO, USA) and was prepared daily by dissolving in saline solution $(0.9 \% \mathrm{NaCl})$ containing $20 \%$ hydroxypropyl cyclodextrin (American Maize-Products Co., Hammond, IN, USA) to a final concentration of 30 $\mathrm{mg} / \mathrm{kg}$. Assay kits for determination of malondialdehyde (MDA, Cat No. NWK-MDA01) were purchased from NWLSS (Vancouver, BC, Canada). Superoxide dismutase (SOD, Cat. No. 706002) and glutathione peroxidase (GPx, Cat NO. 703102) activities were measured using commercial assay kits (Cat. No. 706002, Cayman Chemical, Ann Arbor, MI, USA). ELISA kits used for determining the levels of IL-6 and IL-11 were purchased from RayBio, GA, USA. Assay kits for determination of serum levels of ALT and AST were purchased from Human Co., Germany.
Animals. All experimental procedures were approved by the medical research ethical committee at King Khalid University and according to the Guide for the Care and Use of Laboratory Animals published by the US National Institutes of Health (NIH publication No.85-23, revised 1996). Sprague Dawley rats $(n=18)$ weighing 170 $200 \mathrm{~g}$ were used in this study. All rats were bred and housed in the research center of King Khalid University, College of Medicine (Abha, Saudi Arabia), at temperatures of 23 $\pm 1^{\circ} \mathrm{C}$ and a $12 \mathrm{~h}$ light: $12 \mathrm{~h}$ dark cycle. Rats had free access to tap water and fed standard laboratory chow during the acclimatization period.

Experimental design. After a one week adaptation period, rats were randomly assigned into 4 groups $(n=6$; each $)$ and were distributed in their corresponding cages and classified as follows: (1) Control group: rats received normal saline daily for 7 days; (2) RES+QUR group: rats were pre-treated with resveratrol (30 mg/kg) (Sener et al., 2006) and $50 \mathrm{mg} / \mathrm{kg}$ quercetin (Murota \& Terao, 2003) FOR 7 days; (3) APAP intoxicated group (Model group): rats received normal saline for 7 consecutive days and then given a single dose of acetaminophen $(2 \mathrm{~g} / \mathrm{kg}$, orally); and (4) RES+QUR+APAP group: rats were pre-treated with resveratrol and quercetin as above for 7 consecutive days and then administered with a single dose of acetaminophen ( $2 \mathrm{~g} / \mathrm{kg}$, orally). Acetaminophen was administered to the desired groups one hour after the last dose of treatment on day 7 and all treatment in all groups were administered i.p. in a final volume of $1 \mathrm{~mL}$. All animals were sacrificed at day 8 .

Blood samples. At the end of the experimental period, blood samples were collected by cardiac puncture under anesthesia (sodium thiopentone at $40 \mathrm{mg} / \mathrm{kg}$ body weight) after an overnight fast of 12 hours. These blood samples were collected without any anticoagulant, left for 10 minutes, then centrifuged for 10 minutes at $4000 \mathrm{r} / \mathrm{min}$ to obtain serum, which was stored at minus $20^{\circ} \mathrm{C}$ until further biochemical analysis for determination of serum liver injury enzymes ALT and AST according to manufacturer's instructions.

Preparation of liver homogenates. As we previously reported (Al Humayed, 2017), part of the livers obtained from the rats of all groups were freshly washed with phosphate buffered saline (PBS), $\mathrm{pH}$ 7.4. Then, they were homogenized with an ultrasonic homogenizer in cold phosphate buffer, pH 7.4, containing ethylene-diaminetetra-acetic acid (EDTA). The supernatant obtained from each rat was aliquot in separate tubes and stored at $-70^{\circ} \mathrm{C}$ for later analysis of levels of Bcl-2, IL-11, IL-6, MDA, SOD, and GPX according to manufacturer's instructions. 
Detection of p53 and Bax mRNAs by reverse transcriptase-polymerase chain reaction (RT-PCR). Total RNAs were isolated from freshly dissected rats' livers using the RNeasy Mini Kit (Qiagen Pty, Victoria, Australia). The RNA was reverse-transcribed for a single strand cDNA synthesis (Invitrogen) and amplified by PCR using primer pairs for $\mathrm{p} 53$, Bax, and $\beta$-actin derived from the published cDNA sequence as previously described by our group (Eleawa et al., 2014). The PCR products were separated by $2 \%$ agarose gel electrophoresis and visualised by ethidium bromide, and gel images were scanned and quantified by densitometry using the NIH image software.

Histological study. Liver specimens were dissected out by midline laparotomy and immediately fixed in $10 \%$ formol saline for 24 hours. Paraffin blocks were processed, sectioned in $5 \mathrm{~mm}$ thickness and subjected to H\&E staining to observe the morphological changes (Al-Hashem et al., 2019).

Statistical analysis. The data were expressed as mean \pm standard deviation (SD). Data were processed and analyzed using the SPSS version 10.0 (SPSS, Inc., Chicago, Ill., USA). One-way ANOVA was done followed by Tukey's post hoc test. Pearson correlation statistical analysis was performed for detection of a probable significance between two different parameters. Results were considered significant if $\mathrm{p} \leq 0.05$.

\section{RESULTS}

Induction of acute liver injury in rats by acetaminophen. The disease was induced in the model group of rats by acetaminophen overdose ( $2 \mathrm{~g} / \mathrm{kg}$ body weight), which was confirmed 24 hours post acetaminophen ingestion as demonstrated by abnormal liver tissue architecture, a significant decrease in hepatic antioxidant, and a sharp increase in liver injury enzymes (Fig. 1). Acetaminophen induced hepatotoxicity caused a twofold decrease in the levels of the antioxidant GPx (Fig. 1A), and an increase in ALT (Fig. 1B, a fivefold increase) and AST (Fig. 1C, a sevenfold increase) compared to normal levels in the control group. H\&E stained images of liver tissues from the model group revealed cytoplasmic vacuolation of hepatocytes, pericentral necrotic areas, infiltrating inflammatory cells, and haemorrhage (Fig. 1E) compared with a normal liver parenchyma in the control group (Fig. 1D).
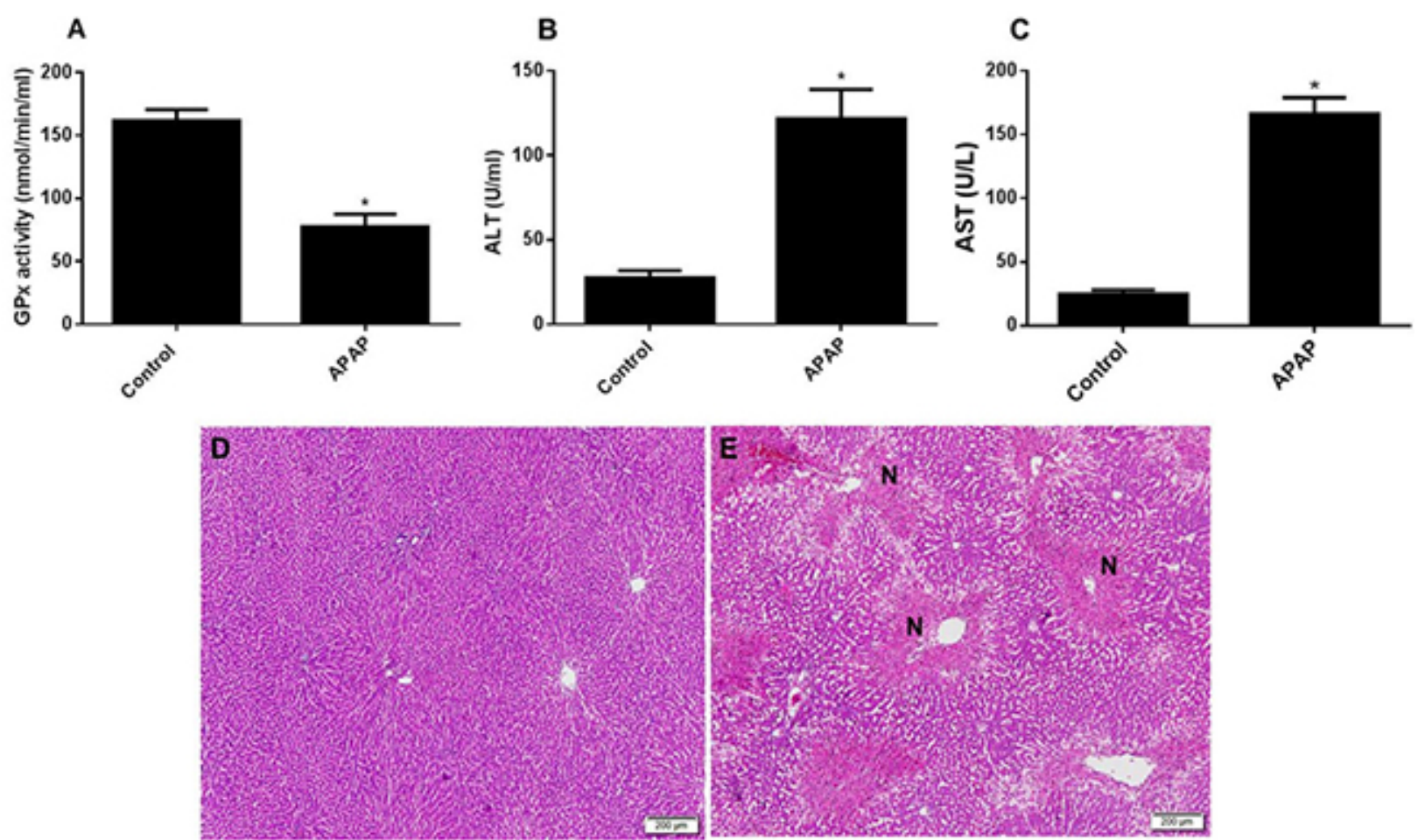

Fig. 1. Induction of acute liver injury in rats by acetaminophen. Liver tissue levels of GPx (A), and blood levels of ALT (B) and AST (C) were measured one day post oral ingestion of rats $(n=6)$ with acetaminophen $(2 \mathrm{gm} / \mathrm{kg}$; model group) compared to vehicle-ingested control group $(n=6)$. Results represent the mean $( \pm S D)$, and experiments were performed in triplicate. $* p<0.0001$ versus control. (D, E). H\&E stained images (x40) of harvested tissues obtained from the liver of the model group (E) compared with the control group (D) of rats are visualized using light microscopy. GPx: Glutathione peroxidase; ALT: alanine aminotransferase; APAP: acetaminophen; N: pericentral necrotic areas. 
Resveratrol plus quercetin augment tissue levels of antioxidants, and ameliorate blood levels of liver injury enzymes. To investigate the level of protection to the acetaminophen-induced modulation of these biomarkers by combined injections of resveratrol and quercetin for 7 days prior to acetaminophen hepatic intoxication, we measured SOD, GPx, ALT, and AST in all rat groups. Compared to the control group, acute liver injury induced by acetaminophen significantly $(\mathrm{p}<0.05)$ modulated SOD, GPx, ALT, and AST, which were completely protected by RES+QUR (Table I).

Table I. Effects of resveratrol plus quercetin (RES+QUR) on the modulation of superoxide dismutase (SOD), glutathione peroxidase (GPx), alanine aminotransferase (ALT), and aspartate aminotransferase (AST) by acetaminophen (APAP) in all experimental groups of rats. Values are expressed as Mean \pm SD for 6 rats in each group. Values were considered significantly different at $\mathrm{P}<0.05$.a: Significant in comparison to control; b:Significant in comparison to RES+QUR; c: Significant in comparison to APAP

\begin{tabular}{lllll}
\hline Animal groups & SOD & GPx & ALT & AST (U/L) \\
& $(\mathrm{U} / \mathrm{gm})$ & $(\mathrm{nmol} / \mathrm{min} / \mathrm{ml})$ & $(\mathrm{U} / \mathrm{ml})$ & \\
\hline Control & $22.82 \pm 2.66$ & $161.3 \pm 9.07$ & $27.12 \pm 3.43$ & $24.50 \pm 3.59$ \\
RES+QUR & $44.10 \pm 3.16^{\mathrm{a}}$ & $263.7 \pm 16.55^{\mathrm{a}}$ & $26.74 \pm 2.83$ & $24.73 \pm 3.24$ \\
APAP & $9.98 \pm 3.48 \mathrm{a}^{\mathrm{b}}$ & $77.33 \pm 10.01^{\mathrm{ab}}$ & $121.3 \pm 17.6 \mathrm{a}^{\mathrm{b}}$ & $166.0 \pm 12.98 \mathrm{a}^{\mathrm{b}}$ \\
RES+QUR+APAP & $27.03 \pm 2.22^{\mathrm{bc}}$ & $167.5 \pm 18.35^{\mathrm{bc}}$ & $27.65 \pm 3.13 \mathrm{c}$ & $25.40 \pm 2.96 \mathrm{c}$ \\
\hline
\end{tabular}

A

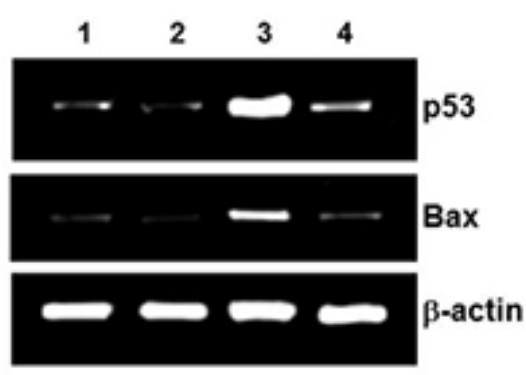

B

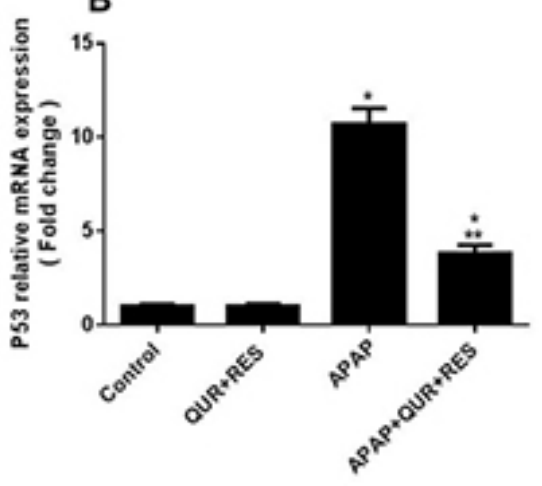

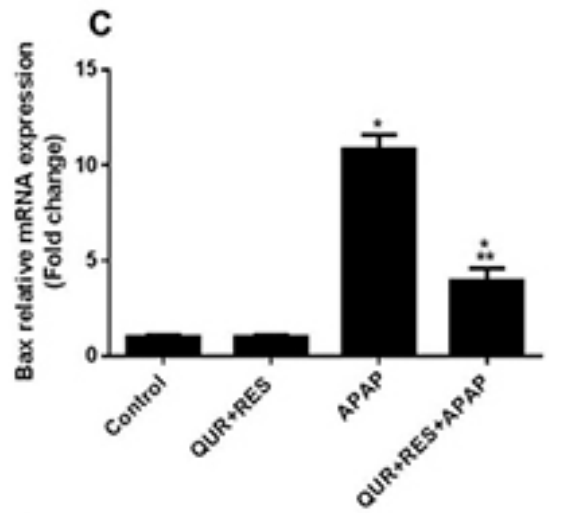
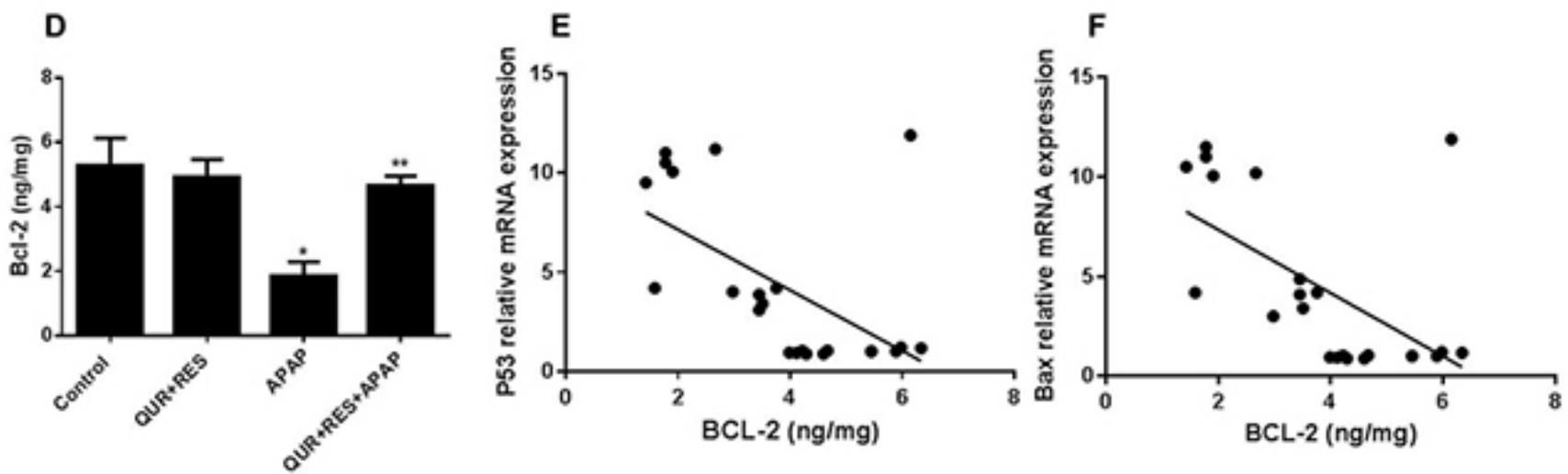

Fig. 2. Resveratrol plus quercetin protects the modulation of pro-apoptotic and anti-apoptotic biomarkers caused by acetaminophen. Liver tissue levels of p53 and Bax gene expression were measured using RT-PCR analysis (A-C), and Bcl-2 protein (D) measured in 4 groups of rats by ELISA one day post liver intoxication by acetaminophen; Control (lane 1 for A), QUR+RES (lane 2 for A), APAP (lane 3 for A), and QUR+RES+APAP (lane 4 for A) groups. Results represent the mean $( \pm S D)$; $n=6$ for each group. Experiments were performed in triplicate. All shown $p$ values are significant. $* p<0.0001$ versus control, $* * p<0.0001$ versus APAP. (E and F) negative correlation between Bcl-2 and p53 (E), and Bcl-2 and Bax (F). p53: tumor suppressor p53; Bax: BCL2 associated X; Bcl-2: B-cell lymphoma 2; APAP: acetaminophen; QUR: quercetin; RES: resveratrol. 
Resveratrol plus quercetin protect acetaminophenmodulated the hepatic apoptosis and survival biomarkers. Apoptosis is triggered by a wide variety of stress and inflammatory stimuli (Yang et al., 2015). We investigated in a rat model of acute liver injury induced by acetaminophen, whether resveratrol plus quercetin can modulate the apoptotic biomarker Bax and the antiapoptotic protein Bcl-2 that are located downstream of p53 in hepatocyte mitochondrial damage (Panasiuk et al., 2006). Thus, we assessed the expression of messenger RNAs for p53 and Bax genes using RT-PCR, and also measured the levels of the survival protein Bcl-2 by ELISA. Acute liver injury induced by acetaminophen augmented p53 (13 fold) and Bax (15 fold) mRNA messages (Fig. 2A-C), and ameliorated Bcl-2 (3 fold) (Fig. 2D). Pre-treatment with resveratrol plus quercetin substantially inhibited p53 (about $70 \%$ reduction; Fig. 2B) and Bax (about $70 \%$ reduction; Fig. 2C) gene expression, and significantly $(\mathrm{p}<0.0001)$ augmented Bcl-2 levels (Fig. 2D). These agents increased Bcl-2 levels comparable with the control levels. Furthermore, a negative correlation between the antiapoptotic protein $\mathrm{Bcl}-2$ scorning and the hepatic levels of apoptotic biomarkers was achieved; Bcl-2 versus p53 ( $\mathrm{r}=-0.576 ; \mathrm{p}=0.004)$ (Fig. $2 \mathrm{E})$, and $\mathrm{Bcl}-2$ versus Bax $(r=-0.590 ; p=0.003)($ Fig. $2 F)$.

Resveratrol plus quercetin reduce acetaminopheninduced biomarkers of oxidative stress and inflammation.
Oxidative stress induced acute liver injury in mice was reported to increase the production of IL-11 by apoptotic hepatocytes to promote the proliferation of healthy surrounding hepatocytes (Nishina et al.). To determine whether the observed acetaminophen-induced apoptosis mentioned above is associated with the upregulation of oxidative stress biomarker and IL-11, which is a member of IL-6 pro-inflammatory family of cytokines, we measured liver tissue levels of MDA (Fig. 3A), IL-6 (Fig. 3B), and IL11 (Fig. 3C) in all animal groups. Acetaminophen significantly $(p<0.05)$ increased these biomarkers, which were completely protected by resveratrol plus quercetin.

We further determined the correlation between IL11 scoring and the hepatic levels of apoptotic and antiapoptotic biomarkers, and oxidative stress in order to further support the link between IL-11, apoptosis, and oxidative stress, and to confirm and characterize that the role of these agents (resveratrol and quercetin) are stable and appropriate agents in liver injury in rats. As shown in Fig. 4, a positive correlation was scored between IL-11 scoring and these biomarkers (Fig. 4A-C) except the antiapoptotic biomarker, Bcl-2 which showed as expected, a negative correlation (Fig. 4D); IL-11 versus p53 ( $\mathrm{r}=0.783$; $\mathrm{p}<0.0001)$, IL-11 versus Bax $(\mathrm{r}=0.781 ; \mathrm{p}<0.0001)$, IL-11 versus MDA $(r=0.933 ; \mathrm{p}<0.0001)$, and IL-11 versus Bcl-2 $(\mathrm{r}=-0.743 ; \mathrm{p}<0.0001)$.
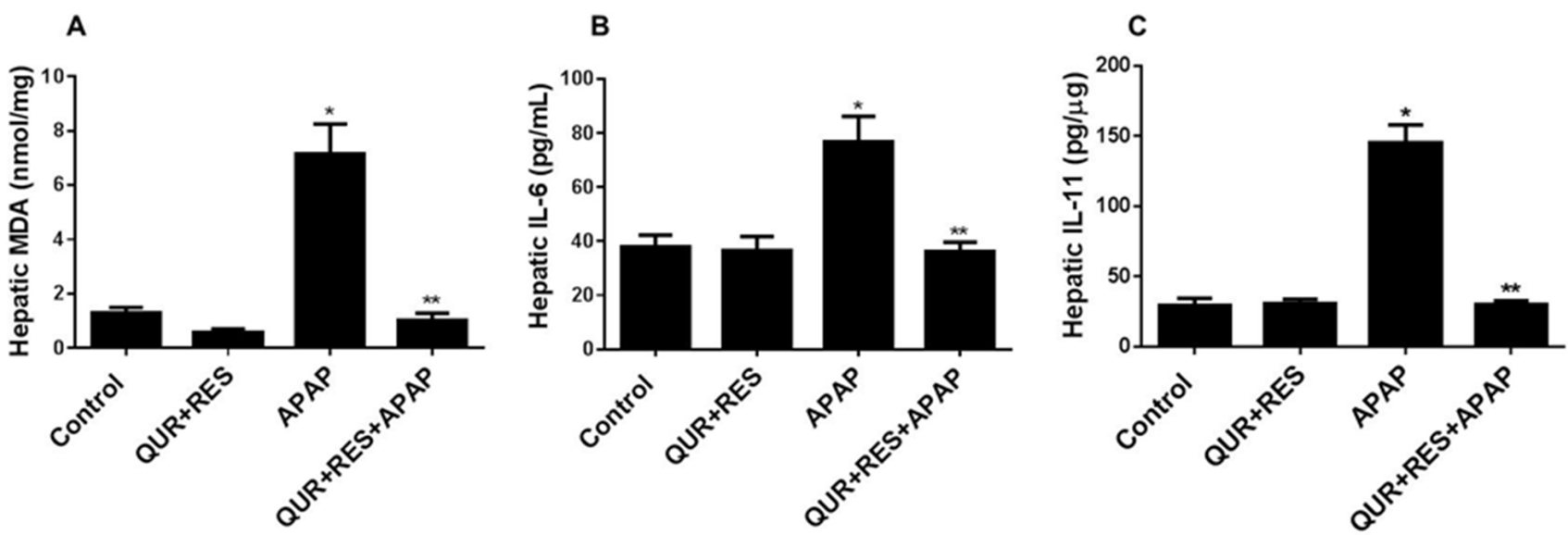

Fig. 3. Resveratrol and quercetin inhibit acetaminophen-induced MDA, IL-6, and IL-11 biomarkers in rats. Liver homogenates levels of MDA (A), IL-6 (B), and IL-11 (C) were measured at the end of the experiment in different groups of rats used in this study; Control group, RES+QUR group, APAP group, and RES+QUR+APAP group. Results represent the mean ( \pm SD); $n=6$ for each group. Experiments were performed in triplicate. ${ }^{*} \mathrm{p}<0.05$ versus control, ${ }^{* *} \mathrm{p}<0.05$ versus APAP. APAP: acetaminophen; QUR: quercetin; RES: resveratrol.

\section{DISCUSSION}

The principal findings in our study were that in a rat model of acute liver injury (i) acetaminophen induced hepatotoxicity modulated all the assessed biomarkers of cell death and survival; (ii) acetaminophen induced 
A

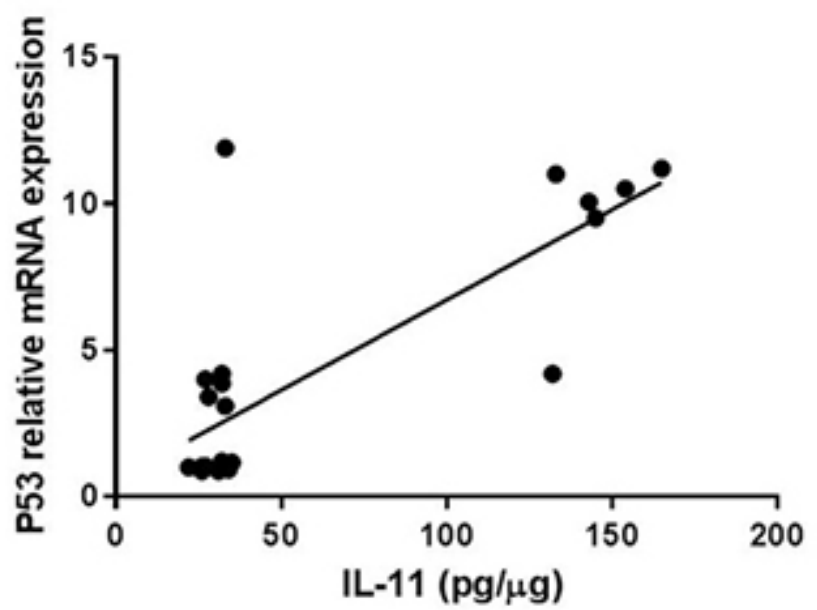

C

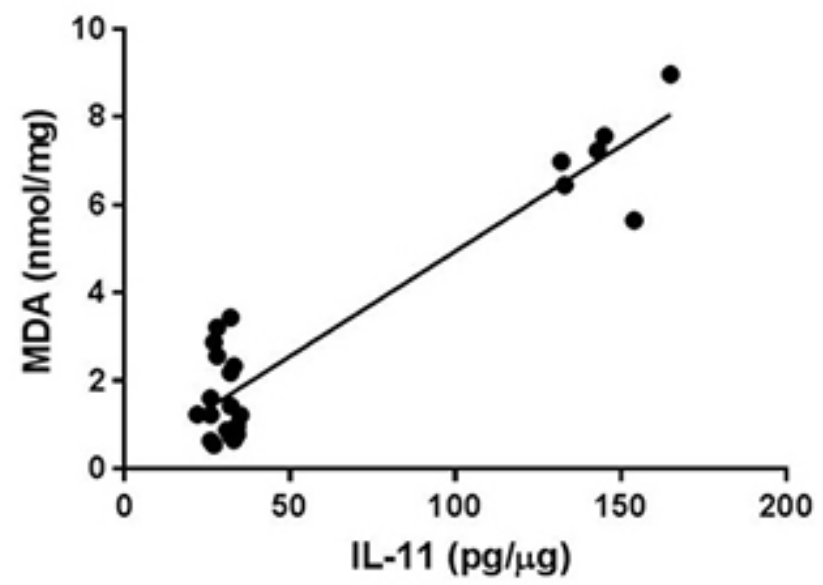

B

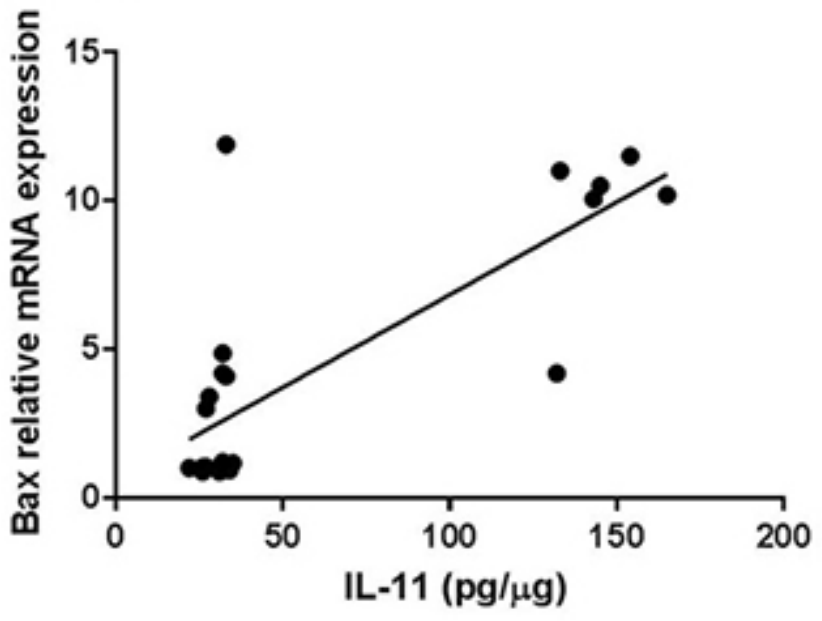

D

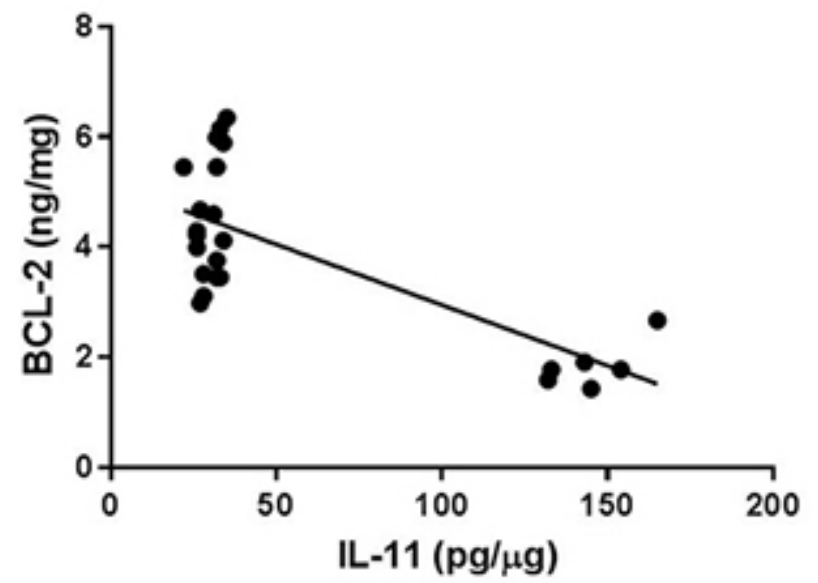

Fig. 4. Correlation between IL-11 scoring and biomarkers of apoptosis, survival, and oxidative stress. Liver IL-11 levels were assessed in all groups of rats one day post liver intoxication by acetaminophen and the correlation between IL-11 and p53, IL-11 and Bax, IL-11 and MDA, and IL-11 and Bcl-2 are shown in (A-D), respectively. IL-11: interleukin-11; p53: tumor suppressor p53; Bax: BCL2 associated X; MDA: malondialdehyde; Bcl-2: B-cell lymphoma 2.

hepatotoxicity augmented the pro-inflammatory cytokine IL11 that provides a functional link between oxidative stress and apoptosis; and (iii) the polyphenolic antioxidant compounds resveratrol plus quercetin were almost completely protected against these hepatotoxicity induced by acetaminophen. These conclusions are supported by the data indicating that acetaminophen-induced acute liver injury (Fig. 1) caused modulation of p53, Bax, and Bcl-2 (Fig. 2), and upregulation of IL-11 and MDA (Fig. 3) that were substantially protected by resveratrol plus quercetin (Figs. 2 and 3). Also, our data that shows a positive correlation between IL-11 scoring and the liver tissue levels of p53, Bax, and MDA (Fig. 4A-C) supports our conclusion mentioned above. Our results were thus consistent with our working hypothesis, which the combined polyphenolic compounds, resveratrol and quercetin can substantially protect against acetaminophen-induced hepatic apoptosis in rats, which is associated with the inhibition of IL-11 and MDA.

Oxidative stress and inflammation are known to be involved in the pathology of acute liver injury in animal models and humans (Jaeschke et al., 2014), and the proinflammatory cytokine IL-11 that is mainly produced by dying hepatocytes upon acute liver injury was reported to provide a functional link between oxidative stress and compensatory hepatocyte proliferation (Nishina et al.). In addition, resveratrol was reported to inhibit p53 and augment 
the survival protein SIRT1 cell signaling to promote hepatocyte proliferation in mice treated with acetaminophen overdose (Wang et al.). These reports are in agreement with our findings of elevated levels of p53, Bax, IL-11, and MDA in acetaminophen-induced acute liver injury, which were protected with resveratrol plus quercetin. Also, our data is in agreement with another study showing acetaminophen overdose induced apoptosis in liver cancer derived cells, human hepatoma cell line, and overexpression of the antiapoptotic protein $\mathrm{Bcl}$ inhibited apoptosis (Boulares et al., 2002).

Our protective approach by pre-treatment with a combination of two antioxidants that almost completely blocked the damaging effects of acetaminophen-induced hepatotoxicity, which were also associated with the suppression of major tissue injury biomarkers, highlight the potential efficacy of resveratrol plus quercetin in controlling, for example, liver injury complications which can arise from the requirement of administering high doses of acetaminophen for a long period of time to patients with chronic illnesses in order to continuously replenish the body with antioxidants that detoxify NAPQI. Indeed, the adverse effects of acetaminophen can be ameliorated by the antioxidant $\mathrm{N}$-acetylcysteine (NAC), which increases GSH and detoxifies NAPQI (Prescott et al., 1977).

In summary, these studies support the conclusion that apoptotic pathway and IL-11 are involved in the pathogenesis of acetaminophen-induced acute liver injury in a rat model of the disease, and resveratrol plus quercetin substantially protects against acetaminophen hepatotoxicity.

\section{ACKNOWLEDGEMENTS}

The author would like to thank Dr. Mariam Al-Ani from Dental Care Partnership, Sutton Coldfield, Birmingham, UK for proofreading the manuscript.

\footnotetext{
AL HUMAYED, S.; AL-ANI, B.; SHATOOR, A. S.; EL KARIB, A. O.; DALLAK, M.; KAMAR, S. S. \& HAIDARA, M. A. Suspensión de la apoptosis hepática inducida por acetaminofén mediante una combinación de resveratrol y quercetina: una asociación de estrés oxidativo e interleucina-11 Int. J. Morphol., 38(1):83-90, 2020.
}

RESUMEN: En el estudio se intentó determinar si los compuestos polifenólicos combinados, el resveratrol y la quercetina pueden proteger sustancialmente contra la modulación de los biomarcadores hepáticos de apoptosis y supervivencia, el eje p53-Bax y el linfoma de células B 2 (Bcl-2) en un modelo animal de lesión hepática aguda inducida por acetaminofén, a través de la asociación del estrés oxidativo y la interleucina-11 (IL-11). El grupo modelo de ratas recibió una dosis única de acetaminofén ( $2 \mathrm{~g} / \mathrm{kg}$ ), mientras que el grupo protector de ratas fue tratado durante 7 días con dosis combinadas de resveratrol $(30 \mathrm{mg} / \mathrm{kg}$ ) y quercetina $(50 \mathrm{mg} / \mathrm{kg}$ ) antes de recibir una dosis única de acetaminofén. Todas los animales fueron sacrificados 24 horas después de la ingestión de acetaminofén. La sobredosis de acetaminofén indujo una lesión hepática aguda, como se observó en el daño profundo del parénquima hepático y el aumento de los niveles de las enzimas en la lesión hepática, alanina aminotransferasa (ALT) y aspartato aminotransferasa (AST). Acetaminofén moduló significativamente $(p \quad<0.05)$ malondialdehído (MDA), p53, regulador de apoptosis Bax, Bcl2, IL-11, interleucina-6 (IL-6), ALT, AST, superóxido dismutasa (SOD) y glutatión peroxidasa ( GPx), los que se encontraron significativamente protegidos por el resveratrol y quercetina. Además se determinó una correlación significativa $(\mathrm{p}<0.01)$ entre la puntuación de IL-11 y los niveles de p53, Bax, Bcl-2 y MDA. En conclusión, el resveratrol más la quercetina protegen de manera efectiva contra la apoptosis inducida por acetaminofén, asociada con la inhibición del estrés oxidativo y la IL-11.

PALABRAS CLAVE: Acetaminofén; Lesión hepática aguda; Apoptosis; Resveratrol; Quercetina; Modelo de rata.

\section{REFERENCES}

Al Humayed, S. Protective and therapeutic effects of Crataegus aronia in non-alcoholic fatty liver disease. Arch. Physiol. Biochem., 123(1):2330, 2017.

Al-Ani, B. Resveratrol inhibits proteinase-activated receptor-2-induced release of soluble vascular endothelial growth factor receptor-1 from human endothelial cells. EXCLI J., 12:598-604, 2013.

Al-Hashem, F.; Al-Humayed, S.; Amin, S. N.; Kamar, S. S.; Mansy, S. S.; Hassan, S.; Abdel-Salam, L. O.; Ellatif, M. A.; Alfaifi, M.; Haidara, M. A.; et al. Metformin inhibits mTOR-HIF-1a axis and profibrogenic and inflammatory biomarkers in thioacetamide-induced hepatic tissue alterations. J. Cell. Physiol., 234(6):9328-37, 2019.

Bertelli, A. A.; Giovannini, L.; Giannessi, D.; Migliori, M.; Bernini, W.; Fregoni, M. \& Bertelli, A. Antiplatelet activity of synthetic and natural resveratrol in red wine. Int. J. Tissue React., 17(1):1-3, 1995.

Blazka, M. E.; Elwell, M. R.; Holladay, S. D.; Wilson, R. E. \& Luster, M. I. Histopathology of acetaminophen-induced liver changes: role of interleukin 1 alpha and tumor necrosis factor alpha. Toxicol. Pathol., 24(2):181-9, 1996.

Boulares, A. H.; Zoltoski, A. J.; Stoica, B. A.; Cuvillier, O. \& Smulson, M. E. Acetaminophen induces a caspase-dependent and Bcl-XL sensitive apoptosis in human hepatoma cells and lymphocytes. Pharmacol. Toxicol., 90(1):38-50, 2002.

Cudmore, M. J.; Ramma, W.; Cai, M.; Fujisawa, T.; Ahmad, S.; Al-Ani, B. $\&$ Ahmed, A. Resveratrol inhibits the release of soluble fms-like tyrosine kinase (sFlt-1) from human placenta. Am. J. Obstet. Gynecol., 206(3):253.e10-5, 2012.

Eleawa, S. M.; Alkhateeb, M. A.; Alhashem, F. H.; Bin-Jaliah, I.; Sakr, H. F.; Elrefaey, H. M.; Elkarib, A. O.; Alessa, R. M.; Haidara, M. A.; Shatoor, A. S.; et al. Resveratrol reverses cadmium chloride-induced testicular damage and subfertility by downregulating p53 and Bax and upregulating gonadotropins and Bcl-2 gene expression. J. Reprod. Dev., 60(2):115-27, 2014. 
Faghihzadeh, F.; Hekmatdoost, A. \& Adibi, P. Resveratrol and liver: A systematic review. J. Res. Med. Sci., 20(8):797-810, 2015.

Frankel, E. N.; Waterhouse, A. L. \& Kinsella, J. E. Inhibition of human LDL oxidation by resveratrol. Lancet, 341(8852):1103-4, 1993.

Hawton, K.; Simkin, S.; Deeks, J.; Cooper, J.; Johnston, A.; Waters, K.; Arundel, M.; Bernal, W.; Gunson, B.; Hudson, M.; et al. UK legislation on analgesic packs: before and after study of long term effect on poisonings. B. M. J., 329(7474):1076, 2004.

Henderson, C. J.; Wolf, C. R.; Kitteringham, N.; Powell, H.; Otto, D. \& Park, B. K. Increased resistance to acetaminophen hepatotoxicity in mice lacking glutathione S-transferase Pi. Proc. Natl. Acad. Sci. U. S. A., 97(23):12741-5, 2000.

Hinson, J. A.; Reid, A. B.; McCullough, S. S. \& James, L. P. Acetaminophen-induced hepatotoxicity: role of metabolic activation, reactive oxygen/nitrogen species, and mitochondrial permeability transition. Drug Metab. Rev., 36(3-4):805-22, 2004.

Hung, L. M.; Chen, J. K.; Huang, S. S.; Lee, R. S. \& Su, M. J. Cardioprotective effect of resveratrol, a natural antioxidant derived from grapes. Cardiovasc. Res., 47(3):549-55, 2000.

Jaeschke, H.; Xie, Y. \& McGill, M. R. Acetaminophen-induced liver injury: from animal models to humans. J. Clin. Transl. Hepatol., 2(3):153-61, 2014.

James, L. P.; Mayeux, P. R. \& Hinson, J. A. Acetaminophen-induced hepatotoxicity. Drug Metab. Dispos., 31(12):1499-506, 2003.

Larson, A. M.; Polson, J.; Fontana, R. J.; Davern, T. J.; Lalani, E.; Hynan, L. S.; Reisch, J. S.; Schiødt, F. V.; Ostapowicz, G.; Shakil, A. O.; et al. Acetaminophen-induced acute liver failure: results of a United States multicenter, prospective study. Hepatology, 42(6):1364-72, 2005.

McGill, M. R.; Sharpe, M. R.; Williams, C. D.; Taha, M.; Curry, S. C. \& Jaeschke, H. The mechanism underlying acetaminophen-induced hepatotoxicity in humans and mice involves mitochondrial damage and nuclear DNA fragmentation. J. Clin. Invest., 122(4):1574-83, 2012.

Murota, K. \& Terao, J. Antioxidative flavonoid quercetin: implication of its intestinal absorption and metabolism. Arch. Biochem. Biophys., 417(1):12-7, 2003

Nishina, T.; Komazawa-Sakon, S.; Yanaka, S.; Piao, X.; Zheng, D. M.; Piao, J. H.; Kojima, Y.; Yamashina, S.; Sano, E.; Putoczki, T.; et al. Interleukin-11 links oxidative stress and compensatory proliferation. Sci. Signal, 5(207):ra5, 2012.

Panasiuk, A.; Dzieciol, J.; Panasiuk, B. \& Prokopowicz, D. Expression of $\mathrm{p} 53, \mathrm{Bax}$ and $\mathrm{Bcl}-2$ proteins in hepatocytes in non-alcoholic fatty liver disease. World J. Gastroenterol., 12(38):6198-202, 2006.

Prescott, L. F.; Park, J.; Ballantyne, A.; Adriaenssens, P. \& Proudfoot, A. $\mathrm{T}$. Treatment of paracetamol (acetaminophen) poisoning with $\mathrm{N}$ acetylcysteine. Lancet, 2(8035):432-4, 1977.

Rogerio, A. P.; Kanashiro, A.; Fontanari, C.; Da Silva, E. V.; LucisanoValim, Y. M.; Soares, E. G. \& Faccioli, L. H. Anti-inflammatory activity of quercetin and isoquercitrin in experimental murine allergic asthma. Inflamm. Res., 56(10):402-8, 2007.

Sener, G.; Toklu, H. Z.; Sehirli, A. O.; Velioglu-Ogünç, A.; Cetinel, S. \& Gedik, N. Protective effects of resveratrol against acetaminopheninduced toxicity in mice. Hepatol. Res., 35(1):62-8, 2006.

Singh, C. K.; Kumar, A.; Hitchcock, D. B.; Fan, D.; Goodwin, R.; LaVoie, H. A.; Nagarkatti, P.; DiPette, D. J. \& Singh, U. S. Resveratrol prevents embryonic oxidative stress and apoptosis associated with diabetic embryopathy and improves glucose and lipid profile of diabetic dam. Mol. Nutr. Food Res., 55(8):1186-96, 2011.

Wang, Y.; Jiang, Y.; Fan, X.; Tan, H.; Zeng, H.; Wang, Y.; Chen, P.; Huang, M. \& Bi, H. Hepato-protective effect of resveratrol against acetaminophen-induced liver injury is associated with inhibition of CYP-mediated bioactivation and regulation of SIRT1-p53 signaling pathways. Toxicol. Lett., 236(2):82-9, 2015.

Yang, Y.; Jiang, G.; Zhang, P. \& Fan, J. Programmed cell death and its role in inflammation. Mil. Med. Res., 2:12, 2015.
Zhang, J.; Sheng, Y.; Shi, L.; Zheng, Z.; Chen, M.; Lu, B. \& Ji, L. Quercetin and baicalein suppress monocrotaline-induced hepatic sinusoidal obstruction syndrome in rats. Eur. J. Pharmacol., 795:1608, 2017.

Corresponding author:

Professor Mohamed Haidara

Department of Physiology

College of Medicine

King Khalid University

Abha 61421

SAUDI ARABIA

Email: haidaram@hotmail.com

Received: 28-05-2019

Accepted: 26-07-2019 